\title{
Estrutura foliar de espécies de Aechmea Ruiz \& Pav. (Bromeliaceae) do Estado de São Paulo, Brasil ${ }^{1}$
}

\author{
Suzana Lúcia Proença ${ }^{2,3}$ e Maria das Graças Sajo ${ }^{2}$
}

Recebido em 06/03/2003. Aceito em 17/09/2003

\begin{abstract}
RESUMO - (Estrutura foliar de espécies de Aechmea Ruiz \& Pav. (Bromeliaceae) do Estado de São Paulo, Brasil). O estudo da estrutura foliar de Aechmea bromeliifolia (Rudge) Baker, A. distichantha Lem., A. ornata Baker, A. nudicaulis (L.) Griseb., A. pectinata Baker, A. coelestis (K. Koch) E. Morren, A. cylindrata Lindm. e A. gracilis Lindm. mostrou que, em todas as espécies, as folhas são hipoestomáticas e revestidas por células epidérmicas de paredes sinuosas e portadoras de corpos silicosos. Apresentam também hipoderme mecânica e aqüífera, escamas nas duas superfícies e canais de aeração, interrompidos por diafragmas de células braciformes, no parênquima clorofiliano. A ocorrência restrita de algumas características permitiu elaborar uma chave de identificação para os representantes estudados. Tais características incluem a ocorrência de grupos de fibras extravasculares, de parênquima paliçádico adaxial, de extensão de bainha nos feixes vasculares de menor calibre, de obstrução nas câmaras subestomáticas, além de variação na espessura da hipoderme aqüífera e no número de células que formam o pedículo das escamas.
\end{abstract}

Palavras-chave: estrutura foliar, Aechmea, Bromeliaceae

\begin{abstract}
Leaf anatomy of Aechmea Ruiz \& Pav. (Bromeliaceae) of São Paulo State, Brazil). The leaf anatomy of Aechmea bromeliifolia (Rudge) Baker, A. distichantha Lem., A. ornata Baker, A. nudicaulis (L.) Griseb., A. pectinata Baker, A. coelestis (K. Koch) E. Morren, A. cylindrata Lindm. and A. gracilis Lindm. was studied. All the leaves are hypostomatic and they present: sinuous walls epidermal cells with silica bodies; aquiferous and mechanical hypodermis; scales on both adaxial and abaxial surfaces; and chlorenchyma with air canals filled with braciforms cells. The restricted occurence of some features allowed us to elaborate a identification key for the studied species. Such characteristics include the presence of extravascular fibrous groups; adaxial palisade parenchyma; smaller vascular bundles with conspicuous extensions of the bundle sheath; oclusion in the substomatic chambers; variation in the thickness of the aquiferous hypodermis, and in the number of stalks cells of the scales.
\end{abstract}

Key words: leaf anatomy, Aechmea, Bromeliaceae

\section{Introdução}

Bromeliaceae é família com representantes predominantemente neotropicais, exceto por Pitcairnia feliciana do oeste africano. Inclui cerca de 54 gêneros e 2.700 espécies, distribuídas em três subfamílias bem definidas: Pitcairnioideae, Tillandsioideae e Bromelioideae (Luther \& Sieff 1996; Smith \& Downs 1974; 1977; 1979), e encontra-se amplamente distribuída no Brasil, principalmente, na Mata Atlântica (Reitz 1983). Reúne plantas herbáceas, geralmente epífitas, com folhas dispostas em rosetas e densamente imbricadas num eixo curto que termina em uma inflorescência, do tipo espiga ou panícula, e onde se observam brácteas de cores vistosas (Tomlinson 1969). A monofilia da família é confirmada por dados moleculares (Chase et al. 2000) e morfológicos
(Dahlgren et al. 1985; Gilmartin \& Brown 1987; Varadarajan \& Gilmartin 1988); todos os seus representantes apresentam escamas foliares peltadas e eretas, número basal de cromossomas $\mathrm{x}=25 \mathrm{e}$ estigmas conduplicados e espiralados (Gilmartin \& Brown 1987; Brown \& Gilmartin 1989).

A anatomia das Bromeliaceae vem sendo estudada com objetivos diversos. Tomlinson (1969), em revisão abrangente, caracterizou cada uma das três subfamílias com base, especialmente, na organização das escamas foliares, dos estômatos e do mesofilo. Alguns estudos apenas descrevem estruturas vegetativas, como os realizados por Krauss (1948; 1949a; b), Braga (1977), Schwartz (1986), Souza \& Neves (1996) e Pita \& Menezes (2002). Outros utilizam a morfo-anatomia para auxiliar no entendimento taxonômico de diferentes grupos da

\footnotetext{
1 Parte da Dissertação de Mestrado da primeira Autora

2 Departamento de Botânica, Instituto de Biociências, Universidade Estadual Paulista, UNESP, Av. 24A, 1515, Bela Vista, C. Postal 199, CEP 13506-900, Rio Claro, SP, Brasil; Bolsa CNPq

3 Autor para correspondência: suzanaproenca@hotmail.com
} 
família, como os desenvolvidos por Robinson (1969), Varadarajan \& Gilmartin (1988), Gilmartin et al. (1989) e Sajo et al. (1998). As folhas de Bromeliaceae também são amplamente estudadas do ponto de vista fisiológico (Benzing 1970; Coutinho 1970; Benzing \& Dahle 1971; Benzing et al. 1976; Nyman et al. 1987; Medina 1990; Loeschen et al. 1993) e as escamas foliares têm sido investigadas com objetivos diversos (Benzing \& Burt 1970; Benzing 1976; Benzing et al. 1978; Strehl 1983).

O gênero Aechmea Ruiz \& Pav. pertencente à subfamília Bromelioideae, ocorre desde o México e Antilhas até o Uruguai e Norte da Argentina (Reitz 1983). Agrupa 172 espécies em oito subgêneros (Smith \& Downs 1979), sendo que para o Estado de São Paulo são registradas 12 espécies, distribuídas em quatro subgêneros. Representa um grupo de difícil delimitação infra-genérica (Wendt 1993) e necessita de estudos taxonômicos abrangentes, que incluam a morfologia polínica e a anatomia foliar (Sousa \& Wanderley 2000). Com o objetivo de apontar possíveis características estruturais que auxiliem na delimitação taxonômica do grupo, foi estudada a anatomia foliar de oito espécies de Aechmea, ocorrentes no Estado de São Paulo.

\section{Material e métodos}

Os espécimes encontram-se depositados nos herbários do Departamento de Botânica/UNESP Câmpus de Botucatu (BOTU), do Instituto de Botânica de São Paulo (SP) e do Jardim Botânico do Rio de Janeiro (RB), sob as seguintes especificações: Subgênero Macrochordion (De Vriese) Baker: Aechmea bromeliifolia (Rudge) Baker, C.J. Campos 01 (BOTU). Subgênero Platyaechmea (Baker) Baker: Aechmea distichantha Lem., G. Martinelli et al. 15852 (RB, SP). Subgênero Pothuava (Baker) Baker: Aechmea ornata Baker, G. Martinelli et al. 15785 (RB, SP); Aechmea nudicaulis (L.) Griseb., F.F.A. Aguiar s.n. (BOTU); Aechmea pectinata Baker, F.F.A. Aguiar s.n. (BOTU). Subgênero Ortgiesia (Regel) Mez: Aechmea coelestis (K. Koch) E. Morren, G. Martinelli et al. 15772 (RB, SP); Aechmea cylindrata Lindm., G. Martinelli et al. 15776 (RB, SP); Aechmea gracilis Lindm., G. Martinelli et al. 15775 (RB). Todos os exemplares são provenientes de ambientes mesofíticos e representam plantas epífitas, ciófilas ou semi-heliófilas.

Para a análise anatômica utilizou-se a quinta folha, retirada no sentido centro-periferia da roseta, que foi fixada em FAA 50 (Johansen 1940) e preservada em álcool etílico $50 \%$. As folhas foram divididas em regiões apical, mediana e basal, da lâmina e bainha foliar, e seccionadas nas porções marginal, intermediária e central. Os cortes transversais e longitudinais, obtidos à mão livre, foram submetidos à dupla coloração com Azul de Astra e Safranina (Bukatsch 1972) e montados em glicerina a $50 \%$. A percentagem de parênquima aquiífero, presente nas três regiões da lâmina foliar, foi estimada utilizando-se fotos de cortes transversais dos representantes estudados.

Para a análise da epiderme foi utilizado o método de dissociação de Ghouse et al. (1972), que consiste na fervura das amostras em solução de ácido nítrico a $50 \%$, neutralizado com $\mathrm{NaOH} 1 \%$; em seguida, as amostras foram lavadas em água destilada, coradas com Safranina e montadas em glicerina a $50 \%$. Utilizou-se ainda a técnica de Franklin (1945), modificada por Berlyn \& Miksche (1976), onde as porções foliares foram colocadas em tubos de ensaio com água oxigenada (30 volumes) e ácido acético glacial na proporção de 1:1 e mantidas em estufa à $60^{\circ} \mathrm{C}$, por cerca de 18 horas. Após este período, as amostras foram lavadas em água corrente, separandose as duas superfícies epidérmicas, que foram coradas com Safranina e montadas em glicerina a $50 \%$. As fotos de vista frontal das escamas foram obtidas após a aplicação de esmalte incolor sobre a superfície foliar, sendo que a película formada foi destacada, obtendo-se com isso a impressão das escamas.

Cortes de material fresco, obtidos à mão livre, foram submetidos ao floroglucinol em meio ácido (Sass 1951), para confirmar a presença de lignina; ao Sudan IV (Gerlach 1984), para verificar a presença de cutina e outras substâncias lipídicas; ao óleo de cravo e cristais de fenol, para confirmar a presença de sílica, nas células da epiderme (Johansen 1940). Para a documentação dos resultados utilizou-se fotomicroscópio Zeiss MC-80 e Leika DM LB com projeção da escala micrométrica.

\section{Resultados}

Todas as folhas estudadas apresentam, nas duas superfícies, escamas (Fig. 1, 4, 12-15) distribuídas ao acaso na região da bainha (Fig. 3, 4) e em sulcos longitudinais nas outras regiões (Fig. 2, 5); tais estruturas são mais freqüentes na superfície adaxial. Os estômatos encontram-se restritos à superfície abaxial, sendo mais numerosos na região da lâmina foliar (Fig. 5) do que na bainha (Fig. 6).

Em vista frontal, a epiderme apresenta células de paredes sinuosas e portadoras de corpos silicosos 

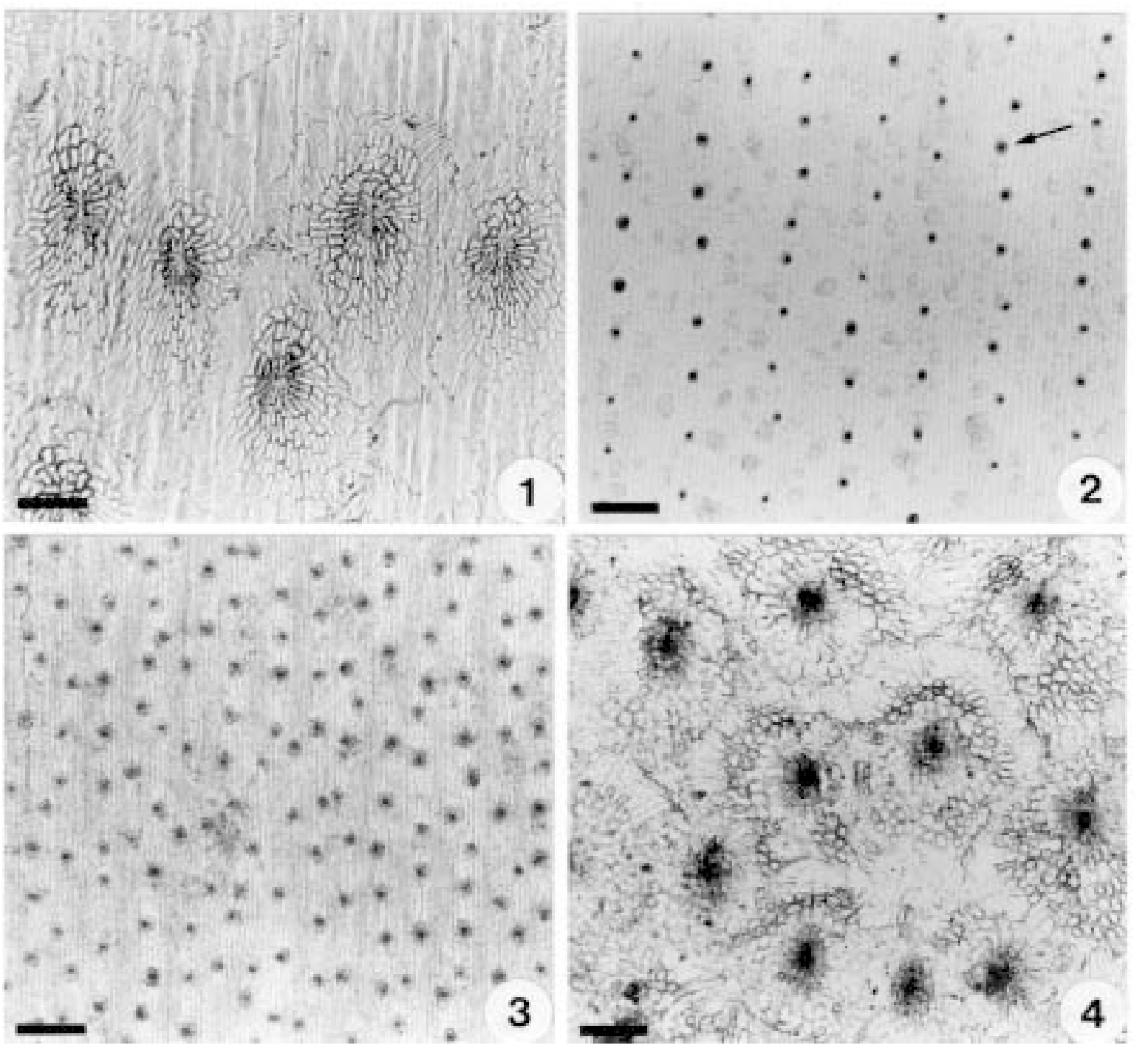

Figuras 1-4. Vista frontal da superfície adaxial de folhas. 1. Aechmea cylindrata (região mediana-central): detalhe das escamas (impressão). 2-3. Aechmea pectinata. 2. Região mediana-central, mostrando as marcas de inserção das escamas, que são distribuídas em fileiras longitudinais (seta). 3. Região central da bainha, mostrando as marcas de inserção das escamas, que são distribuídas ao acaso. 4. Aechmea distichantha (região central da bainha): detalhe das escamas (impressão). Barras: 1 e $4=100 \mu \mathrm{m} ; 2$ e $3=200 \mu \mathrm{m}$.

(Fig. 7). Embora as células subsidiárias laterais e polares não sejam facilmente visíveis, por localizarem-se em nível inferior ao das demais células da epiderme, elas não apresentam paredes sinuosas (Fig. 8).

Observa-se em corte transversal que as duas superfícies da folha são sempre unisseriadas e formadas por células de lúmen reduzido, cujas paredes anticlinais e periclinais internas são muito espessadas e lignificadas (Fig. 9). A superfície abaxial é semelhante à adaxial, diferindo apenas na presença de estômatos, que se situam em depressões (Fig. 10,17). As célulasguarda dos estômatos, localizadas em nível inferior ao das demais células da epiderme, têm paredes internas e externas fortemente espessadas, o que torna seu lúmen muito estreito (Fig. 10). Na região externa das células-guarda nota-se uma saliência em forma de crista, formada pela cutícula, que se projeta sobre a abertura do poro estomático (Fig. 10). Lateralmente e em nível inferior ao das células-guarda observam-se duas células subsidiárias laterais com paredes delgadas (Fig. 10). Embora as células-guarda e as células subsidiárias laterais sejam destituídas de corpos silicosos, observa-se, em corte longitudinal, a presença destas estruturas nas células subsidiárias polares (Fig. 11). A cutícula é relativamente delgada em ambas as superfícies da folha.

As escamas estão inseridas na epiderme pelas células do pedículo, que possuem paredes delgadas e variam de quadrangular a retangular, sendo que a célula 

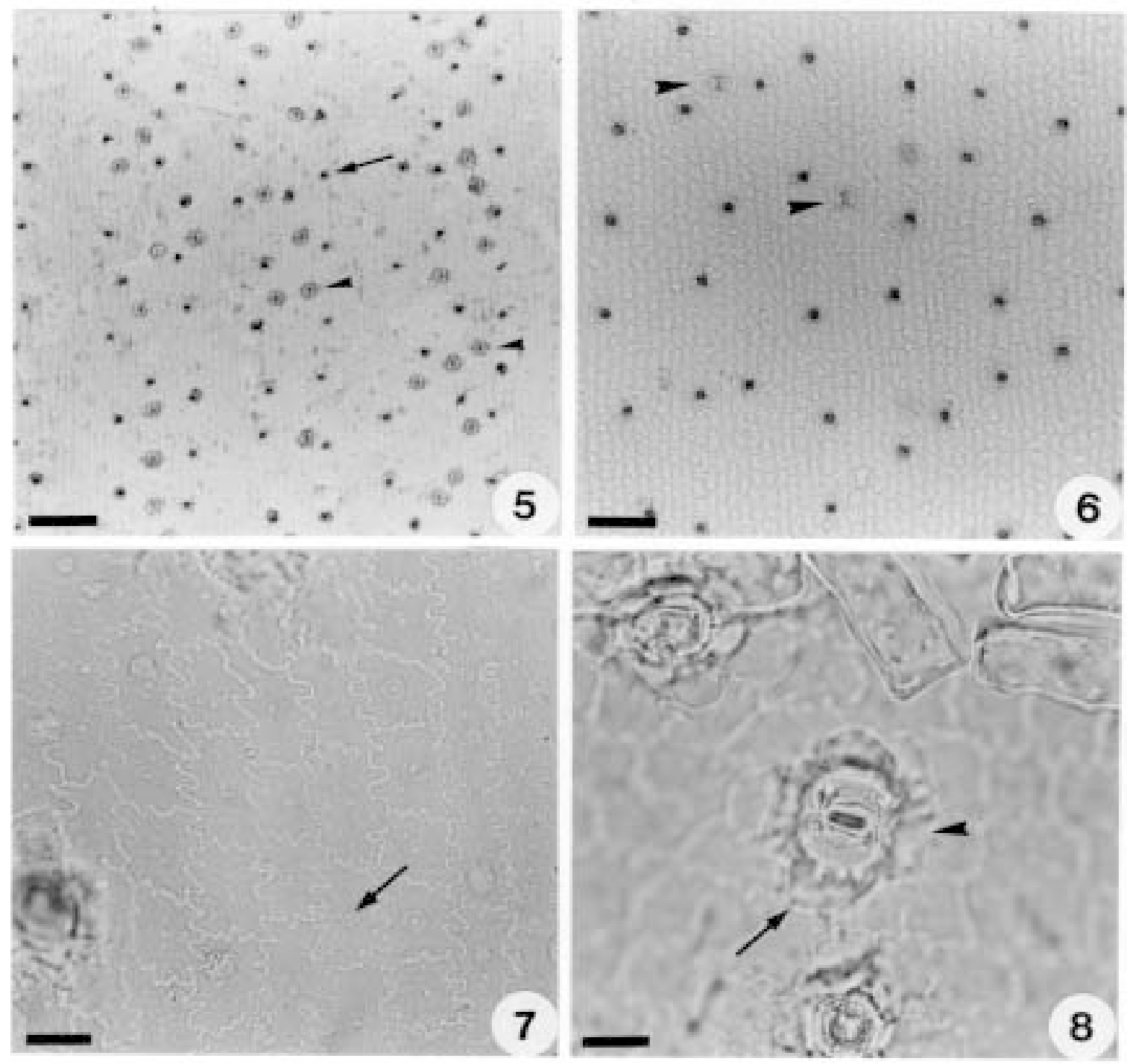

Figuras 5-8. Vista frontal da superfície abaxial de folhas de Aechmea pectinata. 5. Região mediana-central, mostrando marcas de inserção das escamas (setas) e estômatos (pontas de seta) distribuídos em sulcos longitudinais. 6. Região central da bainha, mostrando marcas de inserção das escamas, que se distribuem aleatoriamente e a presença de poucos estômatos (pontas de seta). 7 . Região central da bainha, mostrando células epidérmicas com paredes sinuosas e portadoras de corpos silicosos (seta). 8. Estômato tetracítico, visto em posição interna (adjacente ao mesofilo), evidenciando as paredes lisas das células subsidiárias laterais (seta) e polares (ponta de seta). Barras: 5 e $6=200 \mu \mathrm{m} ; 7$ e $8=20 \mu \mathrm{m}$.

superior apresenta forma quase obcônica e maior dimensão (Fig. 9, 12-15). O número de células que compõem o pedículo varia entre as espécies (Fig. 9, 12-15) e as regiões foliares consideradas (Tab. 1).

Internamente às duas superfícies foliares observa-se, para a região da lâmina de todos os representantes estudados, uma camada de células de formato variado, cujas paredes podem se apresentar pouco ou muito espessadas, esclerificadas e pontoadas (Fig. 16, 17). Na face abaxial das folhas de A. coelestis, A. cylindrata, A. gracilis e A. ornata algumas das células desse tecido são modificadas e aparecem obstruindo as câmaras subestomáticas (Fig. 17; Tab. 2).

Adjacente ao tecido esclerificado da região adaxial observa-se, em todas as folhas estudadas, um parênquima aquíffero, portador de células aclorofiladas de paredes celulósicas, cuja espessura varia numa mesma folha (Fig. 20-21, 23, 26). Na região apical, ele é formado por duas a quatro camadas de células arredondadas ou elípticas e ocupa 25-40\% do mesofilo (Fig. 18-19); nas regiões mediana e basal, suas células são isodiamétricas ou desenvolvidas anticlinalmente e o tecido corresponde a $25-70 \%$ do mesofilo, dependendo da espécie considerada (Tab. 1). Já na 

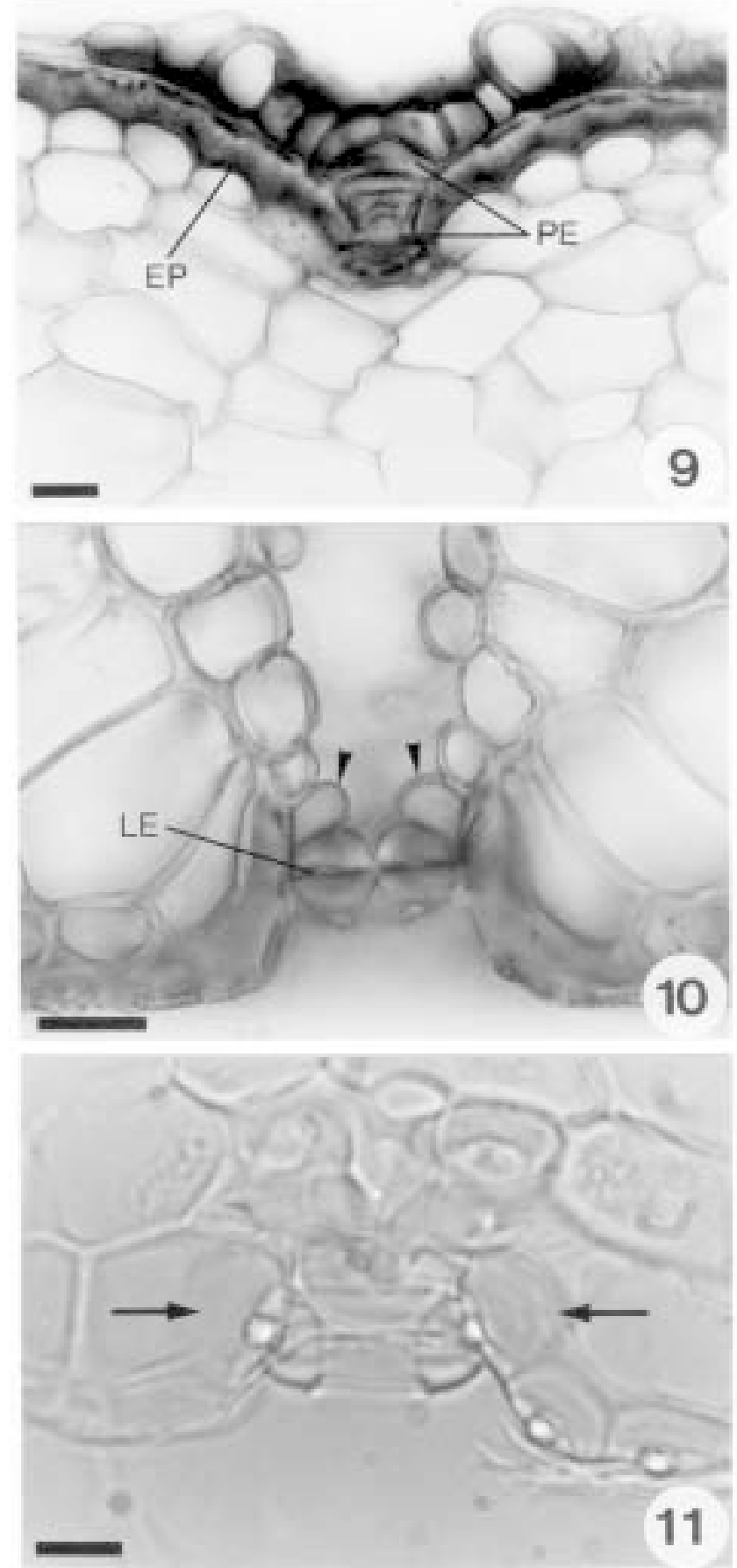

Figuras 9-10. Cortes transversais de folhas. 9. Aechmea nudicaulis (região central da bainha): superfície adaxial, mostrando escama e células com paredes espessadas e lignificadas. 10. Aechmea distichantha (região basal-central): superfície abaxial, evidenciando estômato em depressão, cujas células-guarda apresentam paredes internas e externas fortemente espessadas e projeções de cutícula em forma de crista. Notar as células subsidiárias laterais com paredes delgadas (pontas de seta). Figura 11. Corte longitudinal das folhas de Aechmea coelestis (região mediana-intermediária): superfície abaxial, mostrando corpos silicosos nas células subsidiárias polares (seta) e nas demais células da epiderme. $\mathrm{LE}=$ lúmen estreito; $\mathrm{EP}=$ epiderme $; \mathrm{PE}=$ pedículo da escama. Barras: $9=20 \mu \mathrm{m} ; 10=20 \mu \mathrm{m} ; 11=10 \mu \mathrm{m}$.
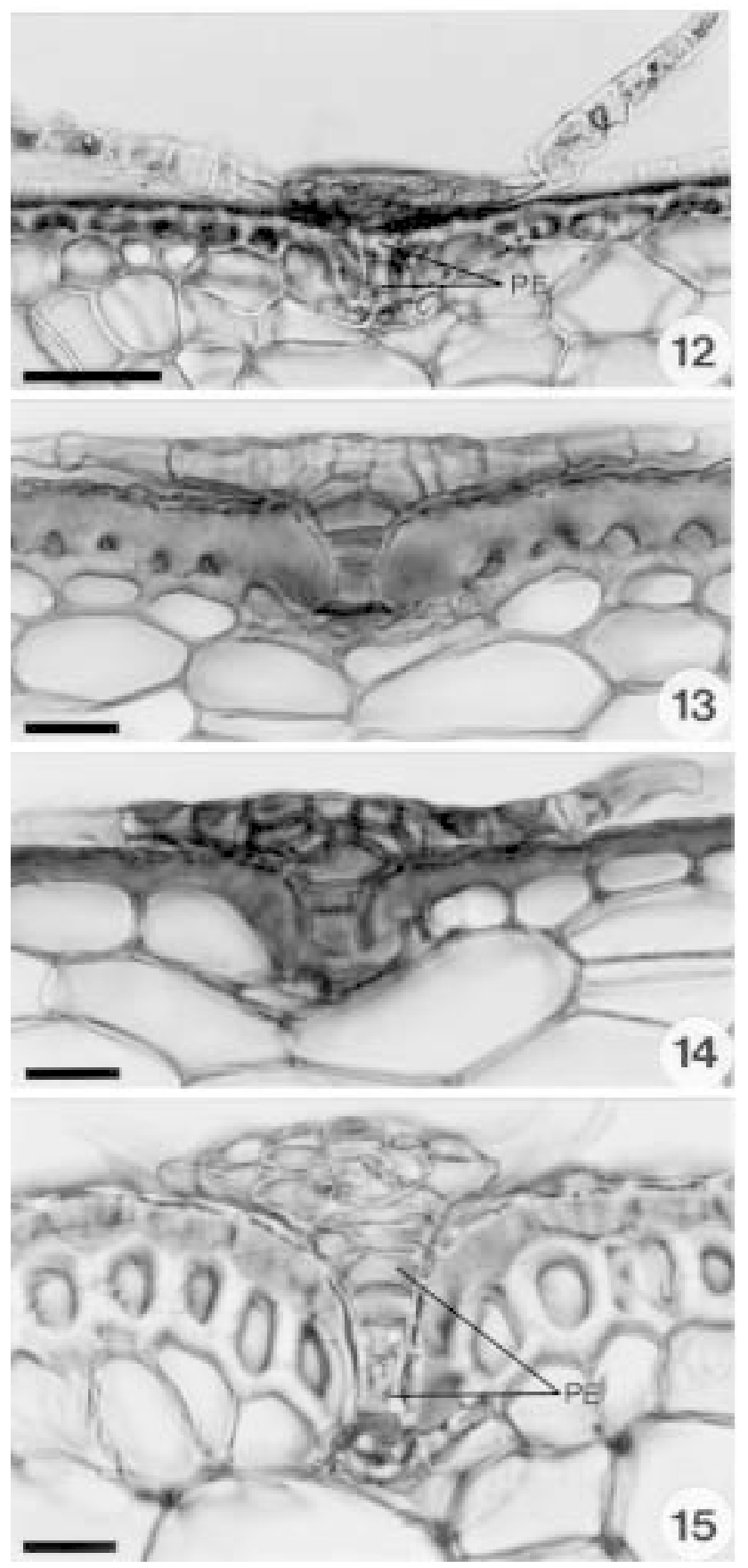

Figuras 12-15. Cortes transversais de folhas (região da bainha), mostrando escamas em detalhe, na superfície adaxial. 12. Aechmea bromeliifolia. 13. Aechmea gracilis. 14. Aechmea distichantha. 15. Aechmea pectinata. PE: pedículo da escama. Barras: $12=60 \mu \mathrm{m} ; 13-15=20 \mu \mathrm{m}$.

bainha as células são arredondadas ou elípticas, e preenchem 20-40\% da espessura do órgão (Fig. 24-25).

O parênquima aqüífero é particularmente desenvolvido em $A$. gracilis e A. distichantha, onde ocupa $50 \%$ do mesofilo na região mediana (Fig. 20) e 60-70\% na região basal (Fig. 21; Tab. 1), e em A. cylindrata (Fig. 22) e A. nudicaulis (Fig. 23) cuja 
Tabela 1. Variação na estrutura das escamas e na espessura do parênquima aqüífero de espécies de Aechmea (Bromeliaceae) do Estado de São Paulo.

\begin{tabular}{|c|c|c|c|c|c|c|}
\hline \multirow[t]{2}{*}{ Subgênero } & \multirow[t]{2}{*}{ Espécies } & \multicolumn{2}{|c|}{$\begin{array}{l}\text { Número de células do } \\
\text { pedículo das escamas }\end{array}$} & \multicolumn{3}{|c|}{ \% de parênquima aquíífero na lâmina foliar } \\
\hline & & Lâmina foliar & Bainha foliar & Região apical & Região mediana & Região basal \\
\hline \multirow[t]{3}{*}{ Ortgiesia } & A. coelestis & 4 & 4 & 25 & 25 & $30-40$ \\
\hline & A. cylindrata & 3 & $3-4$ & 25 & 25 & 50 \\
\hline & A. gracilis & 3 & 3 & $30-40$ & 50 & $60-70$ \\
\hline \multirow[t]{3}{*}{ Pothuava } & A. nudicaulis & 4 & 5 & 25 & $30-40$ & 50 \\
\hline & A. pectinata & 3 & 4 & 25 & 25 & $30-40$ \\
\hline & A. ornata & 3 & $4-5$ & 25 & 25 & $30-40$ \\
\hline Macrochordion & A. bromeliifolia & 2 & 2 & 25 & 25 & $30-40$ \\
\hline Platyaechmea & A. distichantha & 3 & 3 & 25 & 50 & $60-70$ \\
\hline
\end{tabular}
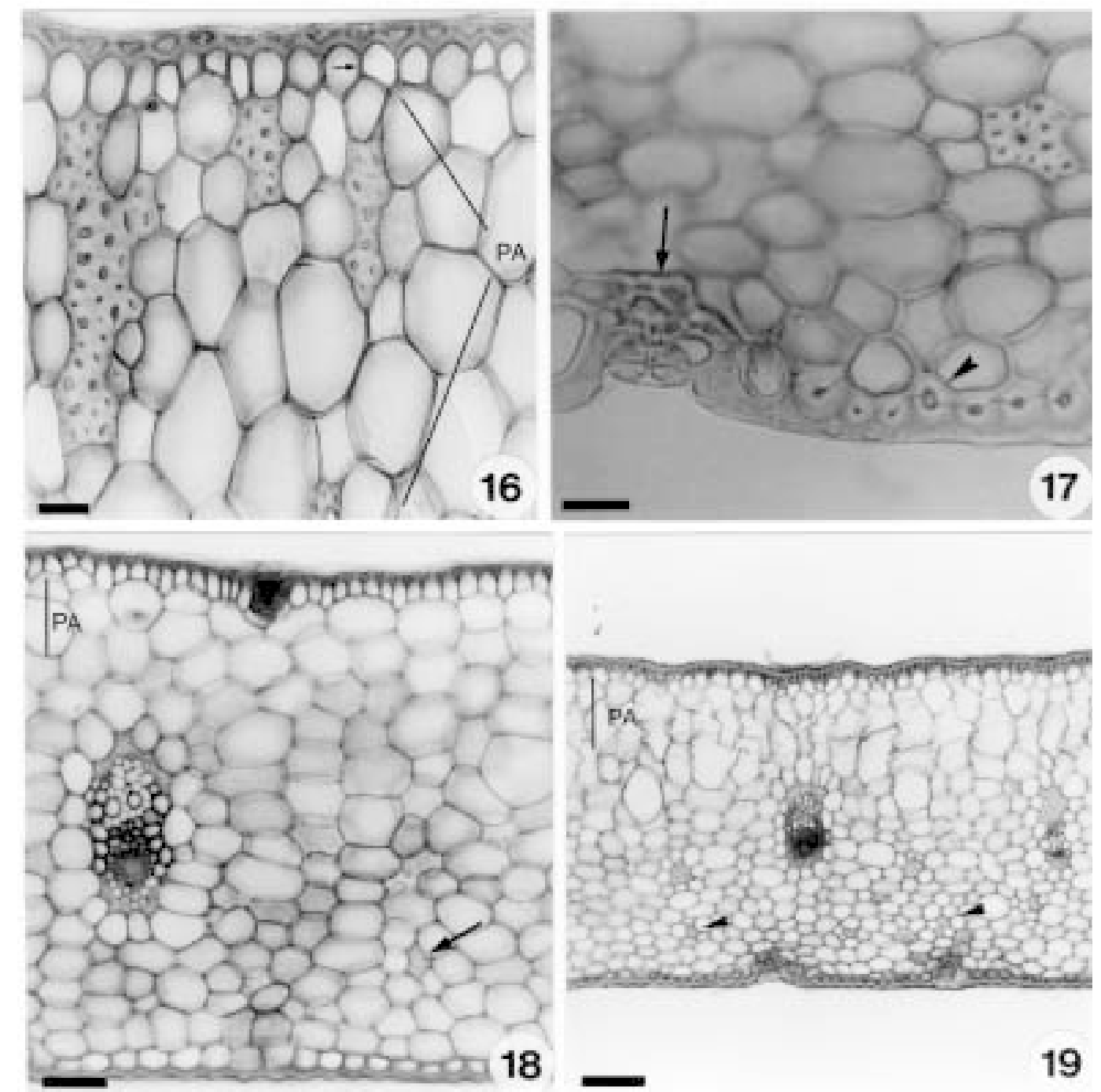

Figuras 16-19. Cortes transversais de folhas. 16. Aechmea ornata (região apical-marginal): células da hipoderme adaxial com paredes pouco espessadas (seta) e grupos de fibras imersos no parênquima aquíffero. 17. Aechmea cylindrata (região mediana-central): células da hipoderme abaxial com paredes muito espessadas e pontoadas (ponta de seta), e estômato abaixo do nível das demais células da epiderme; notar células modificadas da hipoderme (seta) obstruindo a câmara subestomática. 18-19. Região apical-central. 18. Aechmea coelestis, com parênquima aqüífero pouco desenvolvido, grupo de fibras (seta) imerso no parênquima clorofiliano e ausência de canais de aeração. 19. Aechmea gracilis, mostrando parênquima aqüífero, grupos de fibras extravasculares (pontas de seta) imersos no parênquima clorofiliano e ausência de canais de aeração. PA = parênquima aqüífero. Barras: 16 e $17=20 \mu \mathrm{m} ; 18=50 \mu \mathrm{m} ; 19=100 \mu \mathrm{m}$. 
Tabela 2. Características observadas para as espécies de Aechmea (Bromeliaceae) do Estado de São Paulo.

\begin{tabular}{|c|c|c|c|c|c|c|}
\hline \multirow[t]{2}{*}{ Subgêneros } & \multirow[t]{2}{*}{ Espécies } & \multicolumn{2}{|c|}{ Grupos de fibras extravasculares } & \multirow{2}{*}{$\begin{array}{l}\text { Parênquima } \\
\text { paliçádico }\end{array}$} & \multirow{2}{*}{$\begin{array}{c}\text { Obstrução da câmara } \\
\text { subestomática }\end{array}$} & \multirow{2}{*}{$\begin{array}{c}\text { Extensão de bainha dos } \\
\text { feixes pronunciada }\end{array}$} \\
\hline & & Face adaxial & Face abaxial & & & \\
\hline \multirow[t]{3}{*}{ Ortgiesia } & A. coelestis & - & + & - & + & - \\
\hline & A. cylindrata & - & + & - & + & - \\
\hline & A. gracilis & - & + & - & + & - \\
\hline \multirow[t]{3}{*}{ Pothuava } & A. nudicaulis & - & + & + & - & - \\
\hline & A. pectinata & - & + & - & - & - \\
\hline & A. ornata & + & + & - & + & + \\
\hline Macrochordion & A. bromeliifolia & + & + & + & - & - \\
\hline Platyaechmea & A. distichantha & - & - & - & - & + \\
\hline
\end{tabular}
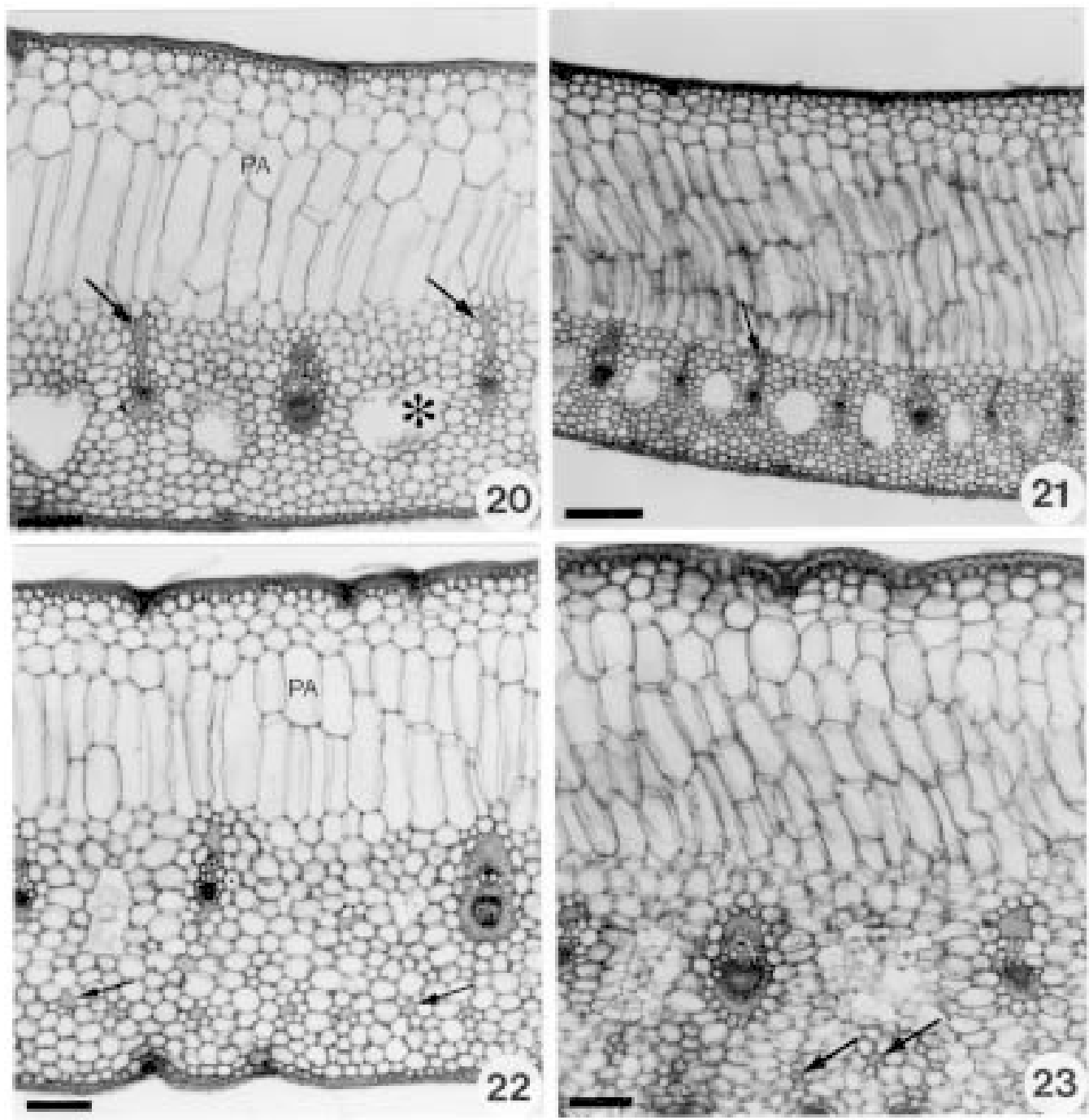

Figuras 20-23. Cortes transversais de folhas, mostrando o aspecto geral do mesofilo. 20-21. Aechmea distichantha. 20. Região mediana-central, mostrando parênquima aqǘfero bem desenvolvido, canais de aeração (asterisco) e feixes vasculares de menor calibre com extensão de bainha pronunciada (setas); notar a ausência de grupos de fibras extravasculares. 21. Região basal-central, com parênquima aqüífero muito desenvolvido, canais de aeração e feixes vasculares de menor calibre com extensão de bainha pronunciada (seta). 22-23. Região basal-central. 22. Aechmea cylindrata, com parênquima aqüífero desenvolvido; as setas indicam grupos de fibras. 23. Aechmea nudicaulis, com parênquima aqüífero desenvolvido; as setas indicam grupos de fibras. PA = parênquima aqǘfero. Barras: $20=200 \mu \mathrm{m} ; 21-23=100 \mu \mathrm{m}$. 
região basal é preenchida por $50 \%$ desse tecido. Nas demais espécies, o parênquima aquiífero é pouco desenvolvido, correspondendo a $25-40 \%$ do mesofilo, em todas as regiões da lâmina (Tab. 1).

O parênquima clorofiliano ocupa a região centroabaxial do mesofilo e é formado por células mais ou menos isodiamétricas (Fig. 18-27). Com exceção do ápice foliar observa-se, nesse tecido e em toda a extensão das lâminas estudadas, a presença de canais de aeração contínuos às câmaras subestomáticas e, ocasionalmente, interrompidos por diafragmas de células braciformes (Fig. 20-28). Na região apical da lâmina, o mesofilo é mais compacto e não ocorrem canais de aeração (Fig. 18-19). O parênquima clorofiliano das folhas de A. bromeliifolia e A. nudicaulis apresentam três a quatro camadas de células em paliçada na face adaxial das regiões mediana e apical (Fig. 26; Tab. 2).

Os feixes vasculares são colaterais e dispostos em uma única série (Fig. 19-27), sendo que os de maior calibre são envolvidos por bainha de células com paredes espessadas e pontoadas que, em geral, também aparecem entre o xilema e floema (Fig. 29). Nos feixes menores, as células esclerificadas ocorrem apenas como extensões de bainha, que se estendem de forma pronunciada, em direção à
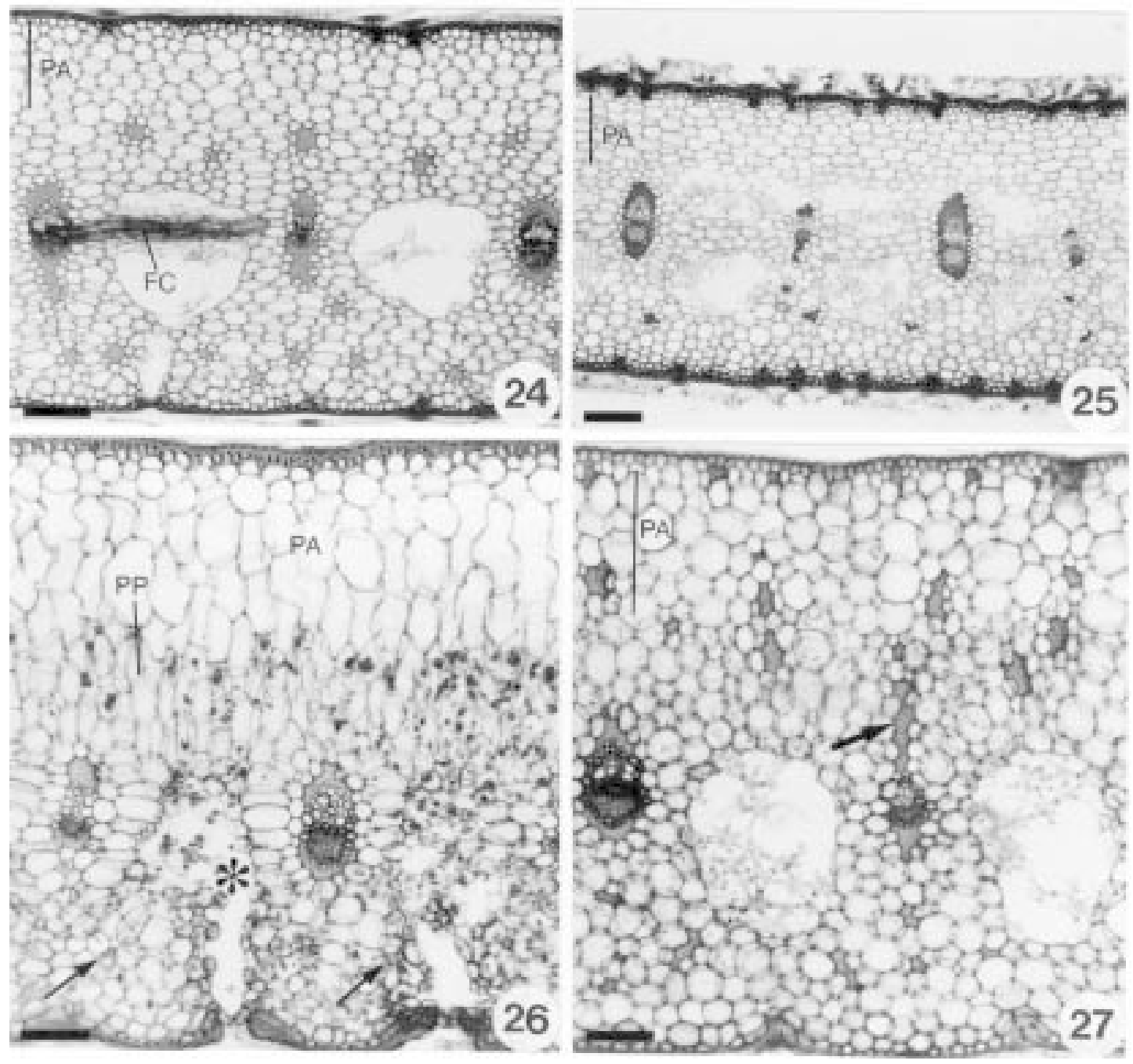

Figuras 24-27. Cortes transversais de folhas, mostrando o aspecto geral do mesofilo. 24-25. Região central da bainha. 24. Aechmea bromeliifolia, mostrando parênquima aquífero, grupos de fibras extravasculares dispersos no parênquima clorofiliano, canal de aeração contínuo à câmara subestomática e feixe comissural. 25. Aechmea pectinata, mostrando parênquima aquífero e grupos de fibras extravasculares dispersos no parênquima clorofiliano. 26. Aechmea nudicaulis (região mediana-central): evidenciando parênquima aqüífero, parênquima paliçádico, canais de aeração contínuos às câmaras subestomáticas (asterisco) e grupos de fibras extravasculares (setas). 27. Aechmea ornata (região basal-central), mostrando feixe vascular de menor calibre com extensão de bainha pronunciada (seta) e grupos de fibras extravasculares imersos nos parênquimas aqüífero e clorofiliano. $\mathrm{FC}=$ feixe comissural; $\mathrm{PA}=$ parênquima aqüífero; $\mathrm{PP}=$ parênquima paliçádico. Barras: 24 e $25=200 \mu \mathrm{m} ; 26$ e $27=100 \mu \mathrm{m}$. 
superfície adaxial, nas folhas de A. distichantha e A. ornata (Fig. 20-21, 27; Tab. 2). Envolvendo as células esclerificadas da bainha, observa-se uma camada de células parenquimáticas, menores que as células do parênquima clorofiliano (Fig. 29). Feixes comissurais interligam os feixes vasculares longitudinais (Fig. 24).

Grupos de fibras, não associados aos feixes vasculares, são comuns às espécies estudadas (Tab. 2), com exceção de $A$. distichantha (Fig. 20-21). Em $A$. coelestis (Fig. 18), A. gracilis (Fig. 19), A. cylindrata (Fig. 22), A. pectinata (Fig. 25) e A. nudicaulis (Fig. 26), os grupos de fibras aparecem na região abaxial do parênquima clorofiliano (em posição nivelada ou abaixo dos feixes vasculares). Em A. bromeliifolia, esses grupos aparecem dispersos por todo o parênquima clorofiliano (Fig. 24), enquanto que, em A. ornata, eles ocorrem também no parênquima aquíf́ero (Fig. 16, 27).
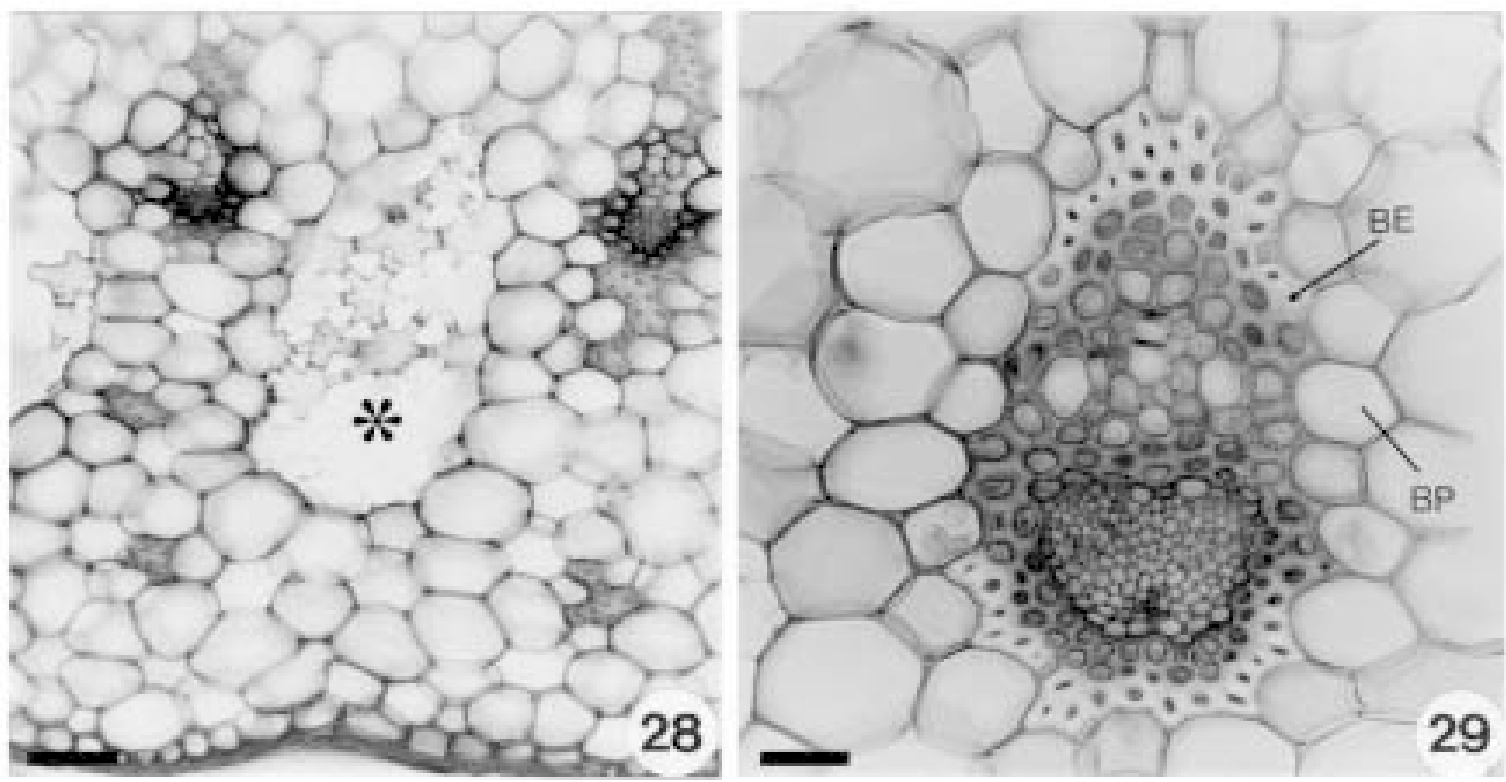

Figuras 28-29. Cortes transversais de folhas de Aechmea ornata. 28. Região basal-intermediária: detalhe de um canal de aeração, interrompido por diafragmas de células braciformes (asterisco). 29. Detalhe de feixe vascular. BE: bainha esclerenquimática; BP: bainha parenquimática. Barras: 28 e $29=50 \mu \mathrm{m}$.

\section{Discussão}

Em todas as folhas estudadas é comum a ocorrência de caracteres descritos como freqüentes para Bromeliaceae, por Tomlinson (1969), tais como: escamas peltadas nas duas superfícies, células epidérmicas portadoras de corpos silicosos, estômatos restritos à superfície abaxial e hipoderme diferenciada em tecido mecânico e armazenador de água. De acordo com Tomlinson (1969), as escamas foliares das Bromeliaceae são constituídas por um pedículo unisseriado imerso na epiderme e por uma expansão distal em forma de escudo, que se conecta ao pedículo pelas células do disco central. Segundo o mesmo autor, freqüentemente, a estrutura da escama varia numa mesma folha, especialmente quanto ao número de células que constituem o pedículo. Essa variação também foi observada para as folhas de A. cylindrata, A. nudicaulis, A. pectinata e A. ornata (Tab. 1).
Conforme aqui demonstrado, as escamas das regiões mediana e apical se distribuem em fileiras longitudinais, nas duas superfícies, mas na da bainha essa distribuição é aleatória. Uma vez que distribuição aleatória das escamas caracteriza os representantes da subfamília Tillandsioideae, considerada derivada dentro do grupo (Benzing et al. 1985), Strehl (1983), sugere que tricomas em fileiras seja caráter plesiomórfico para a família.

Com relação à densidade de escamas, pode-se dizer que ela é visivelmente maior na superfície adaxial da bainha do que nas demais regiões da folha. Como todos os representantes aqui estudados apresentam bainha foliar alargada, o que propicia o acúmulo de água na base da roseta, certamente, a maior densidade de escamas nesta região está relacionada com a função de absorção da água, que é armazenada ao longo da folha no parênquima aqüífero. Além disso, a predominância de estômatos na região mediana da 
lâmina, sugere compartimentação foliar já descrita para outras Bromeliaceae (Souza \& Neves 1994) onde a bainha seria o sítio de absorção e a região mediana, o de síntese.

As escamas foliares das Bromeliaceae têm sido consideradas relevantes na adaptação dos diferentes táxons, independentemente do ambiente onde eles ocorrem (Benzing 1980 apud Varadarajan \& Gilmartin 1987). Tomlinson (1969) referindo-se às escamas de Tillandsioideae, consideradas as mais especializadas dentro da família, citou dupla função para essas estruturas: absorção rápida de água e sais minerais, quando úmidas, e redução da transpiração e dos efeitos da insolação, quando secas. Além disso, segundo Benzing (2000), as escamas possuem outras funções, como proteção contra predadores e patógenos, e atração de polinizadores e dispersores, por formarem um denso indumento sobre inflorescências e frutos, que reflete a luz e secreta enzimas digestivas.

Os corpos silicosos, presentes nas células epidérmicas, têm sido associados com a proteção contra o ataque de insetos e patógenos e com o controle da transpiração excessiva (Yoshida et al. 1962; Sangster 1977; Adatia \& Besford 1986).

As células epidérmicas de ambas as superfícies possuem paredes sinuosas, com exceção das células subsidiárias laterais e polares. Para Tomlinson (1969) essas sinuosidades e a forma como a epiderme adere à camada externa da hipoderme representam adaptações que mantêm as camadas superficiais unidas, durante as possíveis expansões e contrações foliares, decorrentes da variação no turgor.

De acordo com Krauss (1949a), a hipoderme esclerificada tem importância mecânica, pois atua reforçando a estrutura foliar. Além disso, o complexo epiderme-hipoderme protege a planta contra a perda de água. Na face abaxial das folhas de A. nudicaulis, A. pectinata, A. bromeliifolia e A. distichantha a hipoderme mecânica aparece interrompida pelas câmaras subestomáticas, enquanto que nas folhas de A. coelestis, A. cylindrata, A. gracilis e A. ornata esse tecido é contínuo e obstrui as câmaras.

O parênquima aquiífero, geralmente, é bem desenvolvido nas regiões mediana e basal da lâmina foliar, e menos pronunciado distal e marginalmente (Tomlinson 1969). Nas espécies aqui estudadas, observa-se parênquima aqüífero apenas na região adaxial e, apesar de todas habitarem ambientes mesofíticos, esse tecido é bastante desenvolvido em A. cylindrata, A. distichantha, A. gracilis $\mathrm{e}$ A. nudicaulis, particularmente nas regiões mediana $\mathrm{e}$ basal da lâmina foliar. Embora Downs (1974) tenha descrito ausência de parênquima aqüífero para A. bromeliifolia, a folha dessa espécie possui três a cinco camadas de células arredondadas, constituindo este tecido. De acordo com Brighigna et al. (1984), a água absorvida pelas escamas é armazenada no parênquima aqüífero, que protege a região clorofiliana contra a intensa luminosidade, favorecendo a fotossíntese e evitando a perda de água através dos canais de aeração.

Em relação ao parênquima clorofiliano, A. bromeliifolia e A. nudicaulis diferem das demais espécies por apresentarem camadas de células em paliçada, nas regiões mediana e apical da lâmina. Downs (1974) acreditou que a presença de parênquima paliçádico não seja freqüiente em Bromeliaceae pois, das 22 espécies por ele estudadas, somente cinco apresentaram este tipo de tecido.

Nas folhas estudadas é comum a ocorrência de canais de aeração, associados às câmaras subestomáticas. Segundo Krauss (1949a), estes canais de aeração constituem um longo sistema de ar, que se estende sem interrupção na folha e fornece uma conexão mais ou menos contínua entre a atmosfera interna e externa. De acordo com Mez (1896 apud Krauss 1949a), os canais de aeração atuam inibindo a transpiração, sem afetar o processo assimilatório.

Os feixes vasculares de maior calibre apresentamse completamente circundados por bainha de células esclerificadas, enquanto que nos feixes menores essas células formam extensões que podem ser mais ou menos pronunciadas, dependendo da espécie considerada (Tab. 2). Van der Merwe et al. (1994) acreditaram que as extensões da bainha dos feixes vasculares desempenhem importante papel na distribuição de água pelo mesofilo e ofereçam sustentação e proteção aos tecidos vasculares. Segundo Mauseth (1988), as extensões da bainha dos feixes vasculares das monocotiledôneas são fibrosas e atuam mais na sustentação da planta do que na pressão de turgor. Ao redor das células esclerificadas ocorre uma bainha parenquimática que corresponde à endoderme, conforme demonstrado por Van Fleet (1961), Pita (1997) e sugerido por Sajo et al. (1998). Como descrito por Pita (1997) e Flores (1975) para outras espécies de Bromeliaceae, é comum a presença de células esclerificadas de procâmbio entre os tecidos vasculares dos feixes de maior calibre.

Como em outros representantes da família (Krauss 1949a; Tomlinson 1969; Flores 1975; Pita 1997), os estômatos são tetracíticos e estão restritos à 
superfície abaxial. Segundo Parkhust (1978), estômatos restritos à superfície abaxial é uma característica comum em plantas de regiões úmidas; entretanto, nas Bromeliaceae, essa característica não parece estar relacionada a aspectos ecológicos, pois os diferentes representantes da família ocupam hábitats diversos e estão sujeitos a condições distintas de umidade, temperatura e luminosidade. Portanto, neste caso, possivelmente folhas hipoestomáticas devam constituir característica plesiomórfica para o grupo.

A subfamília Bromelioideae abriga grande número de gêneros questionáveis devido à imensa variabilidade floral e à falta de estudos mais aprofundados (Benzing 2000). Em relação à Aechmea, determinados autores atentam para a necessidade de se ampliar os conhecimentos sobre o gênero, tanto no aspecto taxonômico quanto no anatômico, palinológico e filogenético, na tentativa de obter dados que auxiliem a compreender a relação existente entre suas espécies, para distribuí-las de forma mais natural dentro dos subgêneros (Wendt 1993; Sousa \& Wanderley 2000).

Como já comentado, as espécies de Aechmea tratadas no presente estudo pertencem a quatro subgêneros: Ortgiesia (A. coelestis, A. cylindrata, A. gracilis); Macrochordion (A. bromeliifolia); Pothuava (A. nudicaulis, A. ornata, A. pectinata) e Platyaechmea (A. distichantha).

Dentro do subgênero Ortgiesia, A. coelestis e A. gracilis são de difícil delimitação pois em ambas, as brácteas do escapo são membranáceas e possuem forma lanceolada e margens inteiras; as inflorescências, ramificadas e subpiramidais, apresentam brácteas florais ovaladas e vermelhas, com ápice atenuado e margens inteiras; as sépalas são assimétricas e conadas na base; as pétalas liguladas são azuladas e possuem ápice obtuso e o ovário é subcilíndrico. A análise de material herborizado, identificados como A. coelestis e A. gracilis, mostram superposição de medidas no comprimento das brácteas, das flores, das pétalas e das sépalas, dificultando também o estabelecimento de limite entre esses táxons. Tal semelhança também acontece na estrutura dos órgãos foliares, embora em A. gracilis o parênquima aqüífero se apresente sempre mais desenvolvido do que em A. coelestis. Embora as folhas de A. cylindrata, que também pertence ao subgênero Ortgiesia, sejam bastante semelhantes às das espécies anteriores, suas inflorescências são distintas: simples, cilíndricas e apresentam brácteas florais estreitamente triangulares; o ovário é elipsóide.

As folhas de A. bromeliifolia, única representante do subgênero Macrochordion no Estado de São Paulo, caracterizam-se por apresentar escamas com apenas duas células no pedículo (três a cinco nas demais espécies estudadas), grupos de fibras extravasculares adjacentes às duas superfícies, e parênquima paliçádico adaxial.

Dentro do subgênero Pothuava, as folhas de A. ornata distinguem-se das demais pela presença de grupos de fibras extravasculares, adjacentes às duas superfícies (somente na abaxial em A. nudicaulis e A. pectinata), de câmara subestomática obstruída (ausente em A. nudicaulis e A. pectinata) e de extensões de bainha nos feixes vasculares menores (ausentes em A. nudicaulis e A. pectinata). As folhas de $A$. nudicaulis diferem das de A. pectinata por apresentarem parênquima palicádico adaxial nas regiões apical e mediana da lâmina (ausente em A. pectinata).

Pothuava agrupa espécies com inflorescência estrobiliforme, mas em A. nudicaulis ela é espiciforme. Por esse motivo Wendt (1993) admitiu que esse táxon apresenta mais afinidade com Ortgiesia, cujas inflorescências são em grande parte do tipo espiga. Já em relação aos órgãos foliares, A. nudicaulis se assemelha às espécies de Ortgiesia aqui estudadas (A. coelestis, A. cylindrata e A. gracilis) pela presença de grupos de fibras extravasculares na superfície abaxial, e pela ausência de extensões da bainha nos feixes vasculares. Entretanto, ao contrário do observado para as Ortgiesia, nas folhas de A. nudicaulis, os estômatos não são obstruídos e ocorre parênquima paliçádico adaxial.

Em A. distichantha, única representante do subgênero Platyaechmea no Estado, as folhas não apresentam grupos de fibras extravasculares e, como em A. ornata (subgênero Pothuava), apresentam extensões da bainha dos feixes.

Considerando-se as características relacionadas nas Tabelas 1 e 2 foi possível elaborar a seguinte chave de identificação para as espécies estudadas.

Chave de identificação para as espécies de Aechmea estudadas

1. Folhas com estômatos obstruídos por células modificadas da hipoderme

2. Grupos de fibras extravasculares presentes nas duas superfícies da folha e feixes vasculares com extensão de bainha pronunciada 
2. Sem essas características

3. Parênquima aqüífero ocupando $60-70 \%$ do mesofilo na região basal da lâmina 5. A. gracilis

3. Parênquima aqüífero ocupando menos de $60 \%$ do mesofilo na região basal da lâmina

4. Parênquima aquíf́ero ocupando $50 \%$ do mesofilo na região basal da lâmina 3. A. cylindrata

4. Parênquima aquífero ocupando $30-40 \%$ do mesofilo na região basal da lâmina 2. A. coelestis

1. Folhas com estômatos não obstruídos

5. Feixes vasculares com extensão de bainha pronunciada e ausência de grupos de fibras extravasculares 4. A. distichantha

5. Sem essas características.

6. Presença de grupos de fibras extravasculares nas duas superfícies da folha 1. A. bromeliifolia

6. Grupos de fibras extravasculares restritos à superfície abaxial.

7. Parênquima paliçádico presente nas regiões mediana e apical da lâmina e parênquima aqüífero ocupando $50 \%$ do mesofilo na região basal da lâmina 6. A. nudicaulis

7. Ausência de parênquima paliçádico em toda a extensão da lâmina e parênquima aquífero ocupando 30-40\% do mesofilo na região basal da lâmina 8. A. pectinata

\section{Agradecimentos}

Ao Conselho Nacional de Desenvolvimento Científico e Tecnológico (CNPq), pela bolsa de Mestrado à primeira Autora e pela bolsa de produtividade em pesquisa à segunda Autora.

\section{Referências bibliográficas}

Adatia, M.H. \& Besford, R.T. 1986. The effects of silicon on Cucumber plants grown in recirculating nutrient solution. Annals of Botany 58: 343-351.

Benzing, D.H. 1970. Foliar permeability and the absorption of minerals and organic nitrogen by certain tank bromeliads. Botanical Gazette 131(1): 23-31.

Benzing, D.H. 1976. Bromeliad trichomes: structure, function and ecological significance. Selbyana 1(4): 330-348.

Benzing, D.H. 2000. Bromeliaceae: profile of an adaptative radiation. Cambridge University Press, Cambridge.

Benzing, D.H. \& Burt, K.M. 1970. Foliar permeability among twenty species of the Bromeliaceae. Bulletin of the Torrey Botanical Club 97(5): 269-279.

Benzing, D.H. \& Dahle, C.E. 1971. The vegetative morphology, habitat preference, and water balance mechanisms of the bromeliad Tillandsia ionantha Planch. The American Midland Naturalist 85(1): 11-21.

Benzing, D.H.; Henderson, K.; Kessel, B. \& Sulak, J. 1976. The absorptive capacities of bromeliad trichomes. American Journal of Botany 63(7): 1009-1014.

Benzing, D.H.; Seemann, J. \& Renfrow, A. 1978. The foliar epidermis in Tillandsioideae (Bromeliaceae) and its role in habitat selection. American Journal of Botany 65(3): 359-365.

Benzing, D.H.; Givnish, T.J. \& Bermudes, D. 1985. Absorptive trichomes in Brocchinia reducta (Bromeliaceae) and their evolutionary and systematic significance. Systematic Botany 10: 81-91.
Berlyn, G.P. \& Miksche, J.P. 1976. Botanical microtechnique and cytochemistry. Iowa State University Press, Ames.

Braga, M.M.N. 1977. Anatomia foliar de Bromeliaceae da campina. Acta Amazônica 7(3): 1-74.

Brighigna, L.; Fiordi, A.C. \& Palandri, M.R. 1984. Structural characteristics of mesophyll in some Tillandsia species. Phytomorphology 34: 191-200.

Brown, G.K. \& Gilmartin, A.J. 1989. Chromosome numbers in Bromeliaceae. American Journal of Botany 76(5): 657-665.

Bukatsch, F. 1972. Bemerkungen zur doppelfärbung Astrablau-Safranin. Mikrokosmos 61(8): 255.

Chase, M.W.; Soltis, D.E.; Soltis, P.S.; Rudall, P.J.; Fay, M.F.; Hahn, W.H.; Sullivan, S.; Joseph, J.; Molvray, M.; Kores, P.J.; Givnish, T.J.; Systma, J. \& Pires, C. 2000. Higherlevel systematic of the monocotyledons: an assesment of current knowledge and a new classification. Pp. 3-16. In: K.L. Wilson \& D.A. Morrinson (eds.). Monocots: Systematic and Evolution. CSIRO, Melbourne.

Coutinho, L.M. 1970. Sobre a assimilação noturna de $\mathrm{CO}_{2}$ em orquídeas e bromélias. Ciência e Cultura 22(4): 364-368.

Dahlgren, R.; Clifford, H.T. \& Yeo, P.F. 1985. The families of the monocotyledons: structure, evolution and taxonomy. Springer-Verlag, Berlin.

Downs, R.J. 1974. Anatomy and physiology. Pp. 2-28. In: L.B. Smith \& R.J. Downs (eds.). Pitcairnioideae (Bromeliaceae), Flora Neotropica. Hafner Press, New York.

Flores, E.M. 1975. Algunos aspectos de anatomia foliar comparada de dos especies de Bromeliaceae (Aechmea mexicana Baker y Hechtia glomerata Zucc.). Revista de Biologia Tropical 23(1): 29-52.

Franklin, G.L. 1945. Preparation of thin sections of synthetic resins and wood-resin composites, and a new macerating method for wood. Nature 155: 51.

Gerlach, D. 1984. Botanische mikrotechnik. Georg Thieme Verlag, Stuttgart. 
Ghouse, A.K. \& Yunus, M. 1972. Preparation of epidermal peels from leaves of Gymnosperms by treatment with hot, $60^{\circ} \mathrm{GL} \mathrm{HNO}_{3}$. Stain Technology 47(6): 322-325.

Gilmartin, A.J. \& Brown, G.K. 1987. Bromeliales, related monocots, and resolution of relationships among Bromeliaceae subfamilies. Systematic Botany 12(4): 493-500.

Gilmartin, A.J.; Brown, G.K.; Varadarajan, G.S. \& Neighbours, M. 1989. Status of Glomeropitcairnia within evolutionary history of Bromeliaceae. Systematic Botany 14(3): 339-348.

Johansen, D.A. 1940. Plant microtechnique. McGraw-Hill Book, New York.

Krauss, B.H. 1948. Anatomy of the vegetative organs of the pineapple, Ananas comosus (L.) Merr. I - Introduction, organography, the stem, and the lateral branch or axillary buds. Botanical Gazette 110(2): 159-217.

Krauss, B.H. 1949a. Anatomy of the vegetative organs of the pineapple, Ananas comosus (L.) Merr. II - The leaf. Botanical Gazette 110(3): 333-404.

Krauss, B.H. 1949b. Anatomy of the vegetative organs of the pineapple, Ananas comosus (L.) Merr. III - The root and the cork. Botanical Gazette 110(3): 550-587.

Loeschen, V.S.; Martin, C.E.; Smith, M. \& Eder, S.L. 1993. Leaf anatomy and $\mathrm{CO}_{2}$ recycling during crassulacean acid metabolism in twelve epiphytic species of Tillandsia (Bromeliaceae). International Journal of Plant Sciences 154(1): 100-106.

Luther, H.E. \& Sieff, E. 1996. An alphabetical list of bromeliad binomials. The Bromeliad Society, Oregon.

Mauseth, J.D. 1988. Planty anatomy. The Benjamin/ Cummings Publishing Company, California.

Medina, J.C. 1990. Eco-fisiologia y evolucion de las Bromeliaceae. Boletín de la Academia Nacional de Ciências, Cordoba 59: 71-100.

Nyman, L.P.; Davis, J.P.; O’Dell, S.J.; Arditti, J.; Stephens, G.C. \& Benzing, D.H. 1987. Active uptake of amino acids by leaves of epiphytic vascular plant Tillandsia pauciflora (Bromeliaceae). Plant Physiology 83: 681-684.

Parkhust, D.F. 1978. The adaptative significance of stomatal occurrence on one of both surfaces of leaves. Journal of Ecology 66: 367-383.

Pita, P.B. 1997. Estudo anatômico dos órgãos vegetativos de Dyckia Schultz f. e Encholirium Mart. ex Schultz f. (Bromeliaceae) da Serra do Cipó - MG. Dissertação de Mestrado. Universidade de São Paulo, São Paulo.

Pita, P.B. \& Menezes, N.L. 2002. Anatomia da raiz de espécies de Dyckia Schult. f. e Encholirium Mart. ex Schult. \& Schult. f. (Bromeliaceae, Pitcairnioideae) da Serra do Cipó (Minas Gerais, Brasil), com especial referência ao velame. Revista Brasileira de Botânica 25(1): 25-34.

Reitz, R. 1983. Bromeliáceas e a malária - bromélia endêmica. Pp.1-559. In: R. Reitz (ed.). Flora Ilustrada Catarinense. Parte 1, fasc. Bromélia.

Robinson, H. 1969. A monograph on foliar anatomy of the genera Connelia, Cottendorfia and Navia (Bromeliaceae). Smithsonian Contributions of Botany 2: 1-41.
Sajo, M.G.; Machado, S.R. \& Carmello-Guerreiro, S.M. 1998. Aspectos estruturais de folhas de bromélias e suas implicações no agrupamento de espécies. Pp. 102-111. In: M.V. Pereira (ed.). Bromélias da Mata Atlântica: Canistropsis. Salamandra Consultoria Editorial Ltda, Rio de Janeiro.

Sangster, A.G. 1977. Characteristics of sílica deposition in Digitaria sanguinalis (L.) Scop. (Crabgrass). Annals of Botany 41: 341-350.

Sass, J.E. 1951. Botanical microtechnique. $3^{\text {rd }}$ ed. Iowa State University Press, Ames.

Schwartz, O.M. 1986. On the vascular anatomy of Tillandsia usneoides (Bromeliaceae). Journal of the Bromeliad Society 36(4): 154-158.

Smith, L.B. \& Downs, R.J. 1974. Pitcairnioideae (Bromeliaceae). Pp. 1-662. In: L.B. Smith \& R.J. Downs (eds.). Flora Neotropica. v. 1. Hafner Press, New York.

Smith, L.B. \& Downs, R.J. 1977. Tillandsioideae (Bromeliaceae). Pp. 663-1492. In: L.B. Smith \& R.J. Downs (eds.). Flora Neotropica. v. 2. Hafner Press, New York.

Smith, L.B. \& Downs, R.J. 1979. Bromelioideae (Bromeliaceae). Pp. 1493-2142. In: L.B. Smith \& R.J. Downs (eds.). Flora Neotropica. v. 3. Hafner Press, New York.

Sousa, G.M. \& Wanderley, M.G.L. 2000. Aechmea Ruiz \& Pav. (Bromeliaceae) do Estado de Pernambuco, Brasil. Acta Botanica Brasilica 14(1): 77-97.

Souza, R.C.O.S. \& Neves, L.J. 1996. Leaf anatomy of four Tillandsia species. Bromélia 3(2): 28-39.

Strehl, T. 1983. Forma, distribuição e flexibilidade dos tricomas foliares usados na filogenia de Bromeliáceas. Iheringia, Série Botânica 31: 105-119.

Tomlinson, P.B. 1969. Comelinales - Zingiberales. Pp.193-294. In: C.R. Metcalfe (ed.). Anatomy of the Monocotyledons. v. 3. Oxford University Press, London.

Van Der Merwe, A.M.; Van Der Walt, J.J.A. \& Marais, E.M. 1994. Anatomical adaptations in the leaves of selected fynbos species. South African Journal of Botany 60(2): 99-107.

Van Fleet, D.S. 1961. Histochemistry and function of the endodermis. The Botanical Review 27(2): 165-220.

Varadarajan, G.S. \& Gilmartin, A.J. 1987. Foliar scales of the subfamily Pitcairnioideae (Bromeliaceae). Systematic Botany 12(4): 562-571.

Varadarajan, G.S. \& Gilmartin, A.J. 1988. Taxonomic realigments within the subfamily Pitcairnioideae (Bromeliaceae). Systematic Botany 13(2): 294-299.

Wendt, T. 1997. A review of the subgenus Pothuava (Baker) Baker of Aechmea Ruiz \& Pav. (Bromeliaceae) in Brazil. Botanical Journal of the Linnean Society 125: 245-271.

Yoshida, S.; Ohnishi, Y. \& Kitagishi, K. 1962. Histochemistry of silicon in rice plant. III. The presence of cuticle-silica double layer in the epidermal tissue. Soil Science And Plant Nutrition 8(2): 1-5. 
